\title{
Food-based strategies to meet the challenges of micronutrient malnutrition in the developing world
}

\author{
Kraisid Tontisirin, Guy Nantel* and Lalita Bhattacharjee† \\ Food and Nutrition Division, Food and Agriculture Organization of the United Nations, FAO-ESNA, \\ C-244 Viale delle Terme di Caracalla, 00100 Rome, Italy
}

\begin{abstract}
The purpose of the present paper is to review the evidence in favour of food-based strategies to meet the challenges of micronutrient malnutrition in the developing world. Increasing dietary diversification is the most important factor in providing a wide range of micronutrients, and to achieve this objective in a development context requires an adequate supply, access and consumption of a variety of foods. Diets in developing countries generally lack many nutrients, including energy (inadequate amounts of food), so that strategies need to also emphasize an increase in total food intake, in addition to a greater variety. Agricultural and food policies tend to be oriented to primary agricultural productions, but they could also be formulated to promote and support home gardens and small livestock production for the explicit purpose of increasing the household consumption of micronutrient-rich foods. The adoption of 'desirable' dietary patterns for nutrition improvement, e.g. appropriately formulated to meet micronutrient needs, could be used in the formulation of agricultural policies and programmes. This process could be achieved through support for integrated farming systems oriented to assuring household food security, but also based on a variety of foods that will meet total dietary (including micronutrient) needs. Thus, availability of energy-rich staples, animal and/or fish as major sources of protein, and vitamin-, mineral- and phytonutrient-rich fruit and vegetables could constitute the types of production envisaged. The cultivation of edible indigenous plants as additional sources of micronutrients could also be added. The low bioavailability of some key micronutrients from foods, such as Fe, are substantially enhanced with the right food combinations and with appropriate food processing and preparation techniques. Simple appropriate technology for the preservation of micronutrientrich foods would need further development and promotion for their year-round availability. Linking community development policies to national programmes for the alleviation of hunger and malnutrition, with an emphasis on increasing the variety of foods consumed, is probably the best strategy for improving micronutrient malnutrition sustainably.
\end{abstract}

\section{Micronutrient malnutrition: Food-based strategies: Dietary diversification:} Developing countries

More than one-third of the world's population suffers from micronutrient malnutrition, which exists as a form of hidden hunger, the effects of which are often overlooked. Commonly-occurring micronutrient deficiencies include Fe-deficiency anaemia, I-deficiency disorders and vitarnin A deficiency, which arise largely due to a habitually low dietary consumption of micronutrients in relation to requirements. This situation is often seen in food-insecure households in much of the developing world. The underlying cause of this inadequate consumption is what needs to be appropriately addressed.
For years FAO has been actively facilitating the process for increasing supply, access and consumption of an adequate quantity, quality and variety of foods for all population groups. This initiative is being undertaken as part of FAO's catalytic role in assisting nations, communities and households towards achieving their overall 'right to food'. FAO promotes and supports food-based programmes and strategies to improve nutrition so that all people can obtain a variety of foods, and meet requirements for energy and macro- and micronutrients to achieve a healthy and productive life. In using food-based approaches FAO 
primarily advocates dietary diversification and fortification (Food and Agriculture Organization and International Life Sciences Institute, 1997). However, it is also recognized that in certain circumstances there is a need for supplementation and other public health measures. Therapeutic, and even broad-based supplementation in high-risk populations, is called for when the situation demands. Despite clear evidence that food-based strategies work to reduce micronutrient malnutrition, support for this approach has been down played. What is needed is a stronger commitment to implementation.

The purpose of the present paper is to review the evidence for food-based strategies to meet the challenges of micronutrient malnutrition in the developing world. It also suggests the need and process for adopting a communitybased approach in implementing food-based strategies as a sustainable mechanism for overcoming micronutrient malnutrition.

\section{Dietary diversification}

An intervention strategy that is sustainable without external support and has an ability to simultaneously combat multiple micronutrient deficiencies is what is urgently needed. Dietary diversification, which is central to foodbased approaches, can meet these needs. This approach includes assessing dietary consumption, expanding and diversifying food production, improving food processing, preservation, storage and marketing, and improving food preparation. This strategy has to be supported with a nutrition education programme. As diets in developing countries do not just lack a single micronutrient, but a wide range of them, strategies should work towards enhancing the total energy and micronutrient intake, in addition to paying attention to the bioavailability of the ingested micronutrients.

\section{Agricultural and food policies}

Current agricultural policies largely emphasize primary agricultural production and do not have micronutrient outcomes among its goals (Combs et al. 1995). Accordingly, the thrust is mainly on staples which provide energy and protein, with much less emphasis on fruit and vegetables which are rich sources of micronutrients. There is also lack of integration at the farm level between plant and animal production. This situation is particularly true for small livestock and fish that are particularly important in improving the micronutrient value of diets of rural communities in developing countries. Opportunities for promoting non-intensive small livestock production, such as raising chickens and ducks, can also fulfil critical niches in the agro ecosystems of developing countries. Effort needs to be directed toward the cultivation and use of edible indigenous plants as sources of micronutrients. Ample evidence exists on the availability of wild foods in communities, particularly local fruit and green leafy vegetables that are rich sources of provitamin $\mathrm{A}$. Foods such as wild greens or insects are not actively cultivated by populations engaged in agricultures, even though they are consumed (Caballero \& Mapes, 1985; Booth et al. 1993).
Governments need to acknowledge that the micronutrient deficiency problem exists and they should take the lead in bringing to public attention the magnitude of the problem, its causes and effects, and possible strategies. A well-developed policy environment could therefore facilitate and support small-scale farming systems that maximize outputs of micronutrient-rich foods, particularly for subsistence-farming households.

\section{Dietary assessment}

Dietary assessment is one of the foremost steps in planning dietary diversification strategies. At national levels estimates of food consumption are generally based on food balance sheets, which provide data on national food availability and not on food consumption. National surveys on household food consumption are useful, and sometimes necessary for comparing patterns in different communities and geographic areas. A diet that is deficient in energy has superimposed on it the problem of micronutrient malnutrition (Food and Agriculture Organization, 2000).

Adoption of desirable dietary patterns can be used as a basis for the formulation of agriculture policies and programmes for promoting the increased production and consumption of micronutrient-rich foods. Food consumption data can be used to track dietary changes and lead to policy decisions to improve the overall quality of the diet. Assessment efforts by nutrition planners can influence the demand for food policy, while nutrition education policies stimulate a demand for judicious food choices (Kearney \& Gibney, 1994).

Within the context of food-based dietary guidelines which have been developed in many Asian countries (Florentino, 1996), there exists a clear need and opportunity to develop and implement simple methods to determine the consumption of micronutrient-rich foods. Several methods (Thompson \& Byers, 1994; Gibson \& Ferguson, 2000) have been widely used in collecting dietary intake data that will provide information on nutritional adequacy. In this way it is possible to identify those micronutrients that may be deficient in the diet.

\section{Dietary bioavailability}

Although Fe may be present in adequate amounts in diets, Fe deficiency can persist because of several factors such as poor absorption with non-haem-Fe from plant sources, the physico-chemical nature of the food, the presence of other dietary constituents that may inhibit absorption and food processing techniques that fail to enhance the bioavailability. There are also nutritional factors such as parasitism and high Fe requirements for women during pregnancy, as a result of menstrual losses and child birth, and also in growing children. The absorption of $\mathrm{Fe}$ is influenced by the amount present, its chemical form, the simultaneous consumption of enhancing or inhibiting factors, and the Fe status as well as the overall nutritional status of the individual. The dietary factors that enhance non-haem-Fe absorption include ascorbic acid, meat, poultry, fish and other seafood, and low $\mathrm{pH}$, i.e. lactic acid (Allen \& Ahluvalia, 1997). 
Ascorbic acid and meat are probably the two most important bioavailability enhancers. Among inhibitors, phytic acid, polyphenols, $\mathrm{Ca}$ and soyabean protein inhibit non-haem-Fe absorption. In developing countries where meat intake is low, ascorbic acid emerges as one of the most important enhancers of $\mathrm{Fe}$ absorption (Seshadri et al. 1985). Preventing vitamin $\mathrm{C}$ losses should therefore become a priority as part of dietary improvement efforts. It is estimated that between approximately half and threequarters of vitamin $C$ originally present in food is most often lost in cooking. Moreover, the vitamin $C$ content of food that has been cooked and left to stand decreases considerably, and reheating reduces it still further. This factor is important because in many households in rural South Asia food for the day is cooked all at the same time, providing two meals that may be eaten as much as $12 \mathrm{~h}$ apart. Under such circumstances it may be difficult to ensure adequacy of vitamin $\mathrm{C}$ intake. To alleviate this situation consumption of fruit and vegetables in their uncooked form should be encouraged, and it is gratifying to see that in several Asian countries the street food vendors sell freshlycut fruit and fruit juices. Such food enterprises certainly need to be encouraged, but also with efforts to maintain good hygienic handling practices.

In the case of $\beta$-carotene, which again in the absence of meat is the major dietary source of vitamin $A$ in developing countries, it is important to consider factors which facilitate or prevent inhibition of its biological utilization. Positive clinical and biochemical responses to provitamin A carotenoids in foods have been observed in many studies conducted among populations with evidence of vitamin A deficiency (Annapurna et al. 1991; Rao Narasinga, 1991). Epidemiological evidence from certain states in India tends to support the idea that there is good bioavailability of dietary carotenoids. In communities which consume adequate quantities of carotene-rich foods as the major source of dietary vitamin A, vitamin A deficiency is rarely seen (Hanumatha Rao et al. 1986; National Nutrition Monitoring Bureau, 2000). When carotene-rich foods are given to vitamin A-deficient subjects with low liver stores and low plasma levels of retinol, elevation of plasma levels of retinol can be demonstrated easily, as shown by Hussain \& El-Tohamy (1988, 1990) and Bulux et al. (1994). It is useful to remember that dark-green leafy vegetables, in addition to their being a major source of vitamin $A$, also provide other nutrients, including folic acid, vitamin $\mathrm{C}, \mathrm{Zn}$ and phytonutrients.

\section{Food combinations}

Absorption of micronutrients is strongly influenced by the combination of foods eaten in a given meal. Appropriate food combinations to increase the amount of non-haem-Fe iron absorbed include foods rich in vitamin $\mathrm{C}$, flesh foods and organ meats or offal of animals, birds, fish and other seafood, provided they are consumed at the same meal. Drinking tea or coffee at the same meal or shortly after has a marked inhibitory effect on $\mathrm{Fe}$ absorption. Often in developing countries monotonous diets are consumed, based on cereals, roots and tubers, with negligible quantities of meat, fish or ascorbic acid. These diets
Table 1. Examples of diets with estimated overall iron bioavailability (Food and Agriculture Organization/World Health Organization, 1988)

\begin{tabular}{ll}
\hline Typical diet & Bioavailability of Fe \\
\hline $\begin{array}{l}\text { Cereal-based, roots or tubers and } \\
\text { legumes, with negligible meat, }\end{array}$ & Low (5\% absorption) \\
fish or ascorbic acid-rich foods. & \\
Cereal-based, roots or tubers, with & Intermediate (10\% \\
small quantities of food of animal origin, & absorption) \\
or containing ascorbic acid, & \\
or a diet with still higher levels of & \\
foods of animal origin or ascorbic & \\
acid but also large amounts of tea & \\
or coffee consumed with meals & High (15\% absorption) \\
Diverse diet containing generous \\
quantities of meat, poultry and fish \\
or foods containing high amounts of \\
ascorbic acid.
\end{tabular}

typically contain a preponderance of foods that inhibit $\mathrm{Fe}$ absorption, such as maize, rice, beans, whole-wheat flour and sorghum. Eating cereals that have been fermented increases Fe absorption.

The bioavailability of non-haem-Fe and $\mathrm{Zn}$ in household diets can be improved by the incorporation of absorption enhancers such as muscle protein, including meat, fish and poultry (Hallberg \& Rossander, 1984), and organic acids such as citric, malic, lactic and tartaric acids (Charlton, 1983). The relative enhancing effect of animal protein varies, but beef reportedly has the highest effect $(220 \%)$, with lamb, pork, liver and chicken having an intermediate effect (about 140\%) and fish having the lowest effect (about $75 \%$; Cook \& Monsen, 1976; Lynch et al. 1989). Inclusion of even a small amount of flesh foods in a meal is likely to increase its fat content, and hence facilitate absorption of provitamin A carotenoids and vitamin A by stimulating bile secretion, mixed micelle formation and chylomicron formation. Without sufficient fat the absorption of carotenoids and vitamin A is limited (Reddy \& Vijayaraghavan, 1995). Table 1 lists examples of typical diets with an estimate of their Fe bioavailability.

Composite meals consumed in different regions vary widely in their dietary constituents and in their potential for enhancing Fe absorption. For example, in rural Malawi, the consumption of a fish-based relish with the afternoon and evening meals will enhance the absorption of $\mathrm{Fe}, \mathrm{Zn}$, vitamin A and fat (Gibson et al. 2000). Availability of $\mathrm{Fe}$ from rice-based diets improves from low to intermediate with the addition of curds or fish. Wheat-based diets generally have a lower bioavailability than those based on rice, but when these enhancers are added, the availability rises above that of rice-based meals.

The diet must contain sufficient fat, protein, energy and other key nutrients for dietary vitamin A to be properly utilized in the body. A good daily dietary mixture can be made up of a staple + pulse + an animal food + green leafy vegetables or an orange-coloured vegetable or fruit. Families should be encouraged to use all these foods to make a meal; some examples are: 
staple + pulse + green leafy vegetables or an orange vegetable or fruit at one meal;

staple + animal food + green leafy vegetable or an orange vegetable or fruit at another meal;

addition of a small amount of fat or oil to give extra energy if none of the other foods in the meal is energy-rich.

\section{Dietary requirements for micronutrients}

Diets of adults and children are made up of diverse food items, composed of some foods which are energy-rich and some which are nutrient-rich but energy-poor. A diet with a nutrient density (based on energy content) which is just barely adequate for an adult cannot meet the $\mathrm{Ca}$ and vitamin A needs of a child, or the Fe and folic acid needs of a pregnant woman, even if consumed in amounts adequate to meet their energy needs. Children and pregnant women will need relatively larger proportions (relative to their requirements for energy-providing foods) of foods rich in vitamin $\mathrm{A}, \mathrm{Fe}, \mathrm{Ca}$ and folic acid, e.g. milk, yellow fruits and green vegetables. This situation is particularly acute with respect to micronutrients such as folic acid, vitamin $B_{12}$ and vitamin A when these nutrients are derived from foods such as fruit and vegetables which do not contribute significantly to energy intake.

\section{Nutrition education through food-based dietary guidelines}

Effective implementation of food-based dietary guidelines at various levels can be particularly effective in promoting the use of appropriate micronutrient-rich foods. Food-based dietary guidelines can be tailored to the needs of vulnerable groups such as pregnant and lactating women, infants and young children. Guidelines for feeding infants and young children need to emphasize exclusive breast-feeding for at least the first 4 months of life, followed by appropriate complementary feeding. Providing a mixture of complementary foods can help to fill the gaps and ensure that children get adequate energy, protein and micronutrients for healthy growth (Table 2).

In the first year of life nutritional requirements are higher than at any time during the entire lifespan. In the first 4-6

Table 2. Example of complementary feeding guidelines*

\begin{tabular}{ll}
\hline 0-4 months & $\begin{array}{l}\text { Exclusive breast-feeding } \\
\text { At 4 months }\end{array}$ \\
5 months & $\begin{array}{l}\text { (Carica papaya) } \\
\text { Add egg yolk, chicken liver, legumes, fish and } \\
\text { dark-green leafy vegetables, or other } \\
\text { vegetables such as ivy gourd (Coccinia } \\
\text { arandis L. Voist) or pumpkin (Cucurbita } \\
\text { maxima) }\end{array}$ \\
$6-7$ months & $\begin{array}{l}\text { Give one complete meal including well-cooked } \\
\text { soft fish or meat }\end{array}$ \\
$8-9$ months & $\begin{array}{l}\text { Give two complete meals } \\
\text { Give three complete meals }\end{array}$
\end{tabular}

* Adapted from Thai complementary feeding guidelines (Tontisirin \& Yamborisut, 1995). months of life the infant's nutritional requirements can be totally satisfied by breast milk, but beyond that period complementary foods need to be introduced to augment energy and nutrient intake. Unless an appropriate choice of complementary foods is given to the young child, micronutrient requirements such as that for $\mathrm{Fe}$ are unlikely to be met. Introduction of foods such as chicken liver, green leafy vegetables and millet-legume based food mixes should be provided as part of the complementary feeding schedule at appropriate ages during the weaning period.

Micronutrient intakes can be raised to meet requirements through diversification in the composition of supplementary foods, especially for diets for which cereals provide over three-quarters of the energy intake (Tontisirin \& Yamborisut, 1995). The use of $40 \mathrm{~g}$ green leafy vegetables daily in weaning foods of infants in Bangladesh has shown positive results even when used in a single meal (Rahman et al. 1993). Of importance for infants, however, is not only the type of foods that are introduced, but also at what period they are introduced. Delayed introduction of complementary foods is widespread in developing countries, and this factor has serious implications with respect to stunting and $\mathrm{Fe}$ deficiency. In India, for example, it has been shown nationally that less than one-third of infants (6-9-month-old children) receive semi-solids (International Institute of Population Studies, 1998). Given the high prevalence of low-birth-weight infants in India and other South Asian countries (about one-third of all newborns), the likelihood of Fe-deficiency anaemia is extremely high. On the other hand, starting complementary feeding too early can reduce the absorption of Fe from breast milk.

Food-based dietary guidelines can also focus on improving the ratio of absorption enhancers:inhibitors in the habitual diet. In cultural contexts where meat is a part of the diet there is, of course, no need to promote the introduction of meat to complement other foods. Meat also provides other important nutrients such as protein, vitamin $\mathrm{A}$ and $\mathrm{Zn}$ (Yip, 1996). Incorporating chicken or fish livers or small dried fish into plant-based diets can result in marked increases in $\mathrm{Fe}$ and $\mathrm{Zn}$ absorption. In Thailand, for example, beef or chicken livers are used to enrich fish chips, a popular locally-produced snack which is prepared from a $2: 1 \mathrm{w} / \mathrm{w}$ mixture of sago flour and tapioca flour, and processed by steaming. One bag of fish-liver chips provides $20-30 \%$ of the recommended dietary. allowance for vitamin $\mathrm{A}$ for preschool children, in addition to being a rich source of haem-Fe and $\mathrm{Zn}$ (K Tontisirin and $\mathrm{P}$ Winichagoon, personal communication).

\section{Food processing and preparation}

At the household level certain food preparation and processing methods need to be promoted to reduce the level of absorption inhibitors or increase the content of absorption enhancers, and thus improve the bioavailability of $\mathrm{Fe}, \mathrm{Zn}$ and provitamin $\mathrm{A}$ in rural diets. Typical food processing methods such as germination, malting and fermentation have been found to enhance $\mathrm{Fe}$ absorption by increasing vitamin $\mathrm{C}$ content or by lowering the tannin or phytic acid content, or both. Germination can bring about a 2 -fold 
increase in bioavailability and malting of minor millets a 5to 10 -fold increase, as shown by in vitro studies (De Maeyer et al. 1989). Mild heat treatment can be used to increase the bioavailability of carotenoids in green leafy vegetables by releasing bound carotenoids from the food matrix and binding proteins. It has also been shown to enhance the absorption of non-haem-Fe and $\mathrm{Zn}$ in tubers but not in cereals and legumes (Marfo et al. 1990). On malting, a process that also involves germination, the loss of phytate is reportedly quite pronounced in certain millets. Germination and malting can improve the bioavailability of $\mathrm{Fe}$ by 8 - to 12-fold. The ionizable Fe contents of chickpeas (Cicer arietinum) and wheat progressively increase with germination of up to 72 h (Prabhavathi \& Rao, 1979; Sankara Rao \& Deosthale, 1980, 1981). Some home-based milling procedures used in Latin America have been reported to increase the $\mathrm{Fe}$ and $\mathrm{Zn}$ bioavailability of cereals, probably through a reduction in phytic acid content (Krause et al. 1993). Soaking of grains and legumes, a fairly typical household practice, has been shown to remove anti-nutrients such as saponins and polyphenols (Kataria et al. 1988), which are potent inhibitors of non-haem-Fe absorption (Brune et al. 1989).

Food preparation methods such as steaming and stir frying are desirable practices for increasing micronutrient bioavailability, and should be promoted accordingly. The addition of appropriate quantities of fat or oil should also be encouraged when preparing foods containing provitamin A-rich sources, in order to facilitate their absorption. The levels and bioavailability of carotenoids in green leafy vegetables, sweet potatoes (Ipomoea batatas), papaya (Carica papaya), carrot and other vegetables vary greatly, and it is therefore advisable to promote the consumption of those varieties that contain higher levels. Foods prepared with appropriate combinations of such vegetables, along with staple grains and/or preformed vitamin A sources such as liver or fish, enhance the vitamin A quality of the meals. Thus, practical cooking methods that maximize retention and bioavailability of carotenoids in foods need to be identified and advocated through nutrition education and extension programmes (Dikshit et al. 1988; Padmavati et al. 1992; Bhattacharjee et al. 1994).

Home-scale food technology such as sun-drying, canning and pickling of fruit and vegetables, as well as preparation of fruit squashes, can help to serve as inexpensive and effective methods of preserving surplus micronutrient-rich foods. Fresh spices and herbs (coriander (Coriandrum sativum) leaves, mint, green chillies etc.) which provide provitamin A can be suitably dried and used as dietary adjuncts or relishes to improve the palatability of meals while at the same time providing dietary provitamin A. Promoting the development of local food preservation and processing facilities are important, and such initiatives should involve both the private sector, local producer and consumer cooperatives.

\section{Food fortification}

Food fortification should support dietary improvement strategies and not be seen as an alternative strategy. FAO's efforts to improve nutrition worldwide are guided by the recommendations made during international meetings and conferences, first from the International Conference on Nutrition (Food and Agriculture Organization/World Health Organization, 1992), and more recently with the goals set by the World Food Summit (Food and Agriculture Organization, 1996). To achieve these goals, emphasis is given to addressing the underlying causes of malnutrition, including micronutrient deficiencies, which most often characterise poverty and inadequate agricultural development, and which in turn leads to food insecurity at household and national levels. Fortification of food with micronutrients is a valid technology within a food-based approach, where existing food supplies and limited access fail to provide adequate levels of the respective nutrients in the diet.

Food fortification is a supportive link to sustainable long-term dietary change in populations. A frequent problem with fortified foods, however, is that some target populations, particularly those located far from urban areas, do not have access to centrally-processed fortified foods. Nevertheless, some technology is now being developed (small mills) that allows small-scale (decentralized) fortification of cereals. Expanding information, education and communication campaigns to educate and generate demand for the fortified food is an essential component for any fortification strategy.

Also needed are food regulations that clearly identify the foods to be fortified, the type and levels of the fortificant, labelling requirements, quality standards and safety. Surveillance programmes then need to be put in place to assure adherence to the regulations. Fortification programmes require a committed partnership between governmental organisations, the food industry, trade organisations, marketing specialists, the scientific community and consumers.

\section{Integrated community-based approaches}

Dietary modification and diversification can best be undertaken through community-based approaches. Such an approach can be used to enhance awareness and understanding of micronutrient deficiency in the community, and help to empower the community to be more self-reliant towards addressing its nutritional problems (Tontisirin \& Gillespie, 1999). The community-based approach focuses on building relationships within the community, involving community members in the planning, implementation, monitoring and evaluation processes which address their nutritional and related problems. It also links the existing service delivery structures and systems (Fig. 1). Facilitators at the District and Sub-District levels working in partnership with the community can help to implement integrated community-based projects which specifically address micronutrient security.

In order to build an efficient and effective communitybased approach, there is usually a need to shift the process of system implementation to include an emphasis on the elimination of micronutrient malnutrition (Tontisirin \& Bhattacharjee, 1999). In fact, this sort of change is necessary to generally increase the coverage of any basic health and related service to the community. It is based on a process of social mobilisation, which involves the selection 


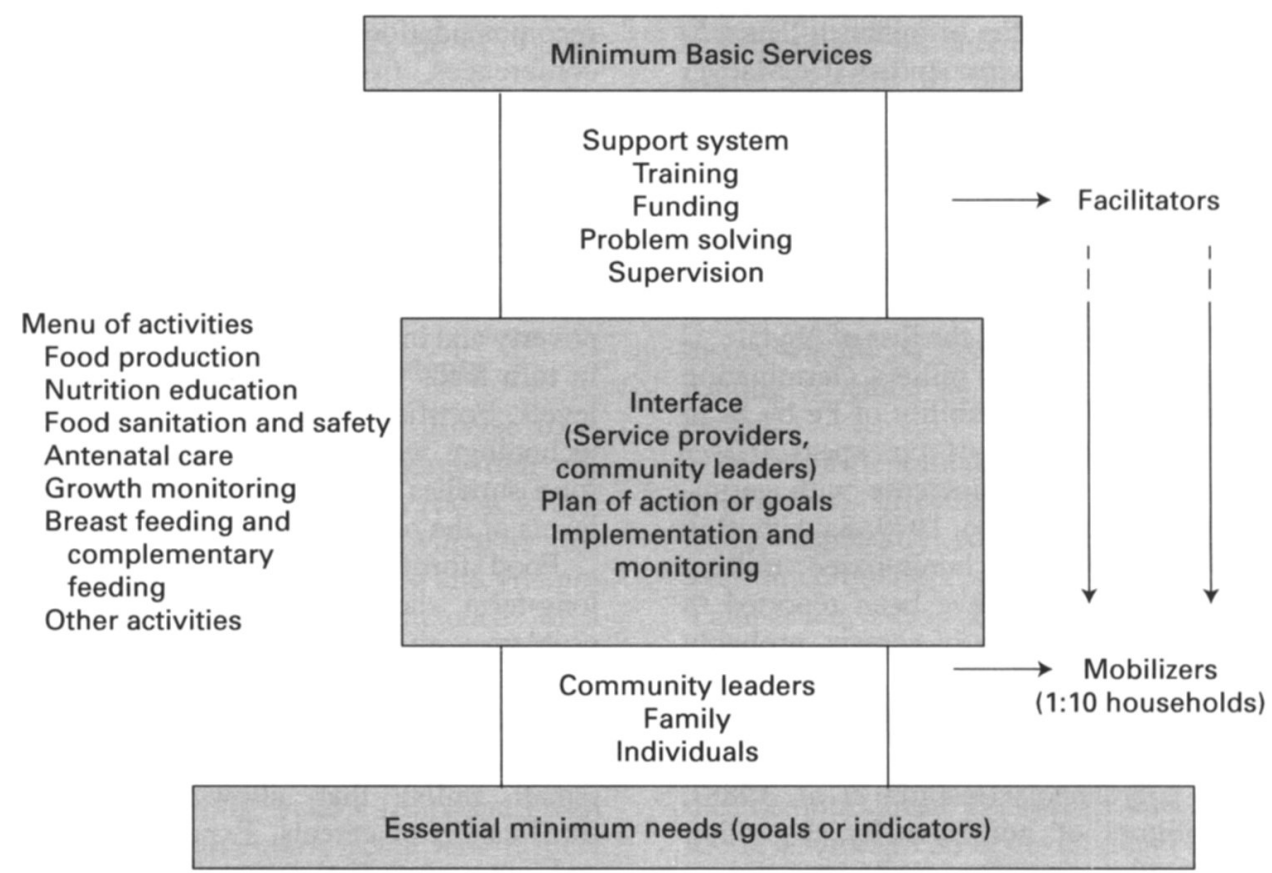

Fig. 1. Community-based approach to dietary modification and diversification, showing the relationships between the existing service delivery structures and systems, and community-based activities.

of community volunteers (mobilizers). The mobilizers, preferably in a low ratio (one volunteer:ten households), can easily inform and encourage, and 'train' individual households to make proper use of available basic services, in order to increase coverage. The objective is to create a demand-driven process that will support gradual acquisition of community self-reliance. Strengthening the interface between service providers and implementers is crucial in optimising such a system. The training and orientation of District level facilitators who are able to develop the capacities of the mobilisers is an essential institutional support structure to enable this approach to become effective and sustainable.

This system, which is based on community mobilisation, can serve to promote community-based food production for consumption, preservation, supplementation and marketing as major activities for nutrition improvement. Programmes that centre around increasing household food production of dark-green leafy vegetables, yellow and orange vegetables and yellow and orange fruits, citrus fruits, raising poultry, egg production, fish ponds and dairy production are all possibilities. Community school gardens can serve as a means of promoting vitamin $\mathrm{A}$ intake and $\mathrm{Fe}$ among children through school projects. These projects serve to enhance their interest in nutrition-linked activities that will contribute to good dietary habits and nutrition improvement. This approach can also be used to prioritise interventions for vulnerable groups such as pregnant women, preschool and school-age children, and the elderly. Monitoring tools can be developed for the purpose (Table 3).

The different sectors need to be well linked in such community-based programmes to build a true multisectoral approach. Public health control measures, including immunisation, control of acute respiratory infections, diarrhoeal diseases and parasitic infestations, education and support for practice of personal hygiene and sanitation, all need to be rigorously promoted simultaneously. Developing a policy which is strongly supportive of the implementation of a community-based programme can, and should, greatly strengthen and improve existing situations.

\section{Conclusion}

There is a need for integrated programmes that address micronutrient deficiencies while simultaneously combating larger issues of food insecurity and malnutrition in the community. Forward-looking food security policies which encourage increased diversity with micronutrient-rich foods at household and community levels need to be implemented. Appropriate food-based strategies should be targeted towards the most vulnerable groups, usually women and children in poor households. Also, most importantly, the period of complementary feeding needs to be appropriately addressed. Intervention efforts also need to be monitored and evaluated effectively in relation to processes and outcomes.

The key challenges include making the elimination of micronutrient deficiencies more demand (community)driven, with support for appropriate food behaviour change. A dietary variety of micronutrient-rich fruit and vegetables also bring with them other naturally-occurring and highlybeneficial phytonutrients. Food-based approaches have a very strong potential for meeting the challenge of reducing and eliminating micronutrient malnutrition. 
Table 3. Inputs and outcomes for prevention and control of micronutrient malnutrition through community-based programmes

\begin{tabular}{|c|c|c|}
\hline Input & Output & Outcome \\
\hline $\begin{array}{l}\text { Dietary improvement: } \\
\text { Food production for consumption; } \\
\text { Information, Education and Communication (IEC); } \\
\text { Complementary food production }\end{array}$ & $\begin{array}{l}\text { No. of home gardens; no. of chicken and } \\
\text { duck raising activities; no. of community } \\
\text { fish ponds; } \\
\text { Consumption of micronutrient-rich foods } \\
\text { (bioavailable) food combinations; } \\
\text { Dietary intake of enhancers; } \\
\text { Avoidance of inhibitors }\end{array}$ & $\begin{array}{l}\uparrow \text { Knowledge, Attitude and Practice (KAP) } \\
\text { towards usage of micronutrient-rich } \\
\text { foods; } \\
\downarrow \text { Micronutrient deficiency prevalence and } \\
\text { gradual elimination major micronutrient } \\
\text { deficiencies (IDA and VAD) }\end{array}$ \\
\hline $\begin{array}{l}\text { Food fortification: } \\
\text { lodized and double-fortified salt; } \\
\text { Other foods }\end{array}$ & $\begin{array}{l}\text { Percentage household usage of iodized/ } \\
\text { double fortified salt; } \\
\text { Percentage individual use }\end{array}$ & $\begin{array}{l}\uparrow \text { KAP towards usage of micronutrient-rich } \\
\text { foods; } \\
\downarrow \text { IDA and IDD prevalence and elimination of } \\
\text { IDA and IDD }\end{array}$ \\
\hline $\begin{array}{l}\text { Basic health services and community participation: } \\
\text { Antenatal Care (ANC), immunization, parasitic } \\
\text { control, hygiene and related activities and } \\
\text { services }\end{array}$ & $\begin{array}{l}\text { Frequency of contacts with pregnant women } \\
\text { (minimum four antenatal case contacts); } \\
\text { Percentage coverage of target groups }\end{array}$ & $\begin{array}{l}\text { Improved pregnancy outcomes (increased } \\
\quad \text { birth weights); } \\
\downarrow \text { IDA prevalence; } \\
\downarrow \text { Worm infestation rates }\end{array}$ \\
\hline Agricultural extension services: & $\begin{array}{l}\text { Mobilizing small farmers, households, } \\
\text { women groups towards food production } \\
\text { activities; } \\
\text { Number of poultry vaccinations events held }\end{array}$ & $\begin{array}{l}\uparrow \text { KAP towards usage of micronutrient-rich } \\
\text { foods; } \\
\uparrow \text { Household income; } \\
\downarrow \text { Prevalence of micronutrient deficiency and } \\
\text { gradual elimination }\end{array}$ \\
\hline
\end{tabular}

FBDG, food-based dietary guidelines; IDA, I-deficiency anaemia; VAD, vitamin A deficiency; IDD, I-deficiency diseases; $\uparrow$, increase; $\downarrow$, decrease.

\section{References}

Allen LH \& Ahluvalia N (1997) Improving Iron Status Through Diet: The Application of Knowledge Concerning Dietary Iron Availability in Human Populations. Washington, DC: US Agency for International Development and Opportunities for Micronutrient Interventions.

Annapurna V, Shah N, Bhaskaram P, Bamji MS \& Reddy V (1991) Bioavailability of spirulina carotene. Journal of Clinical Biochemistry and Nutrition 10, 145-151.

Bhattacharjee LI, Mudambi SR, Bhusan B \& Patanakar AV (1994) Provitamin A content of selected Indian foods. Journal of Food Science and Technology 31, 249-251.

Booth SL, Johns T \& Lopez-Palacios CY (1993) Factors influencing the dietary intake of indigenous leafy greens by the K' ekchi people of Alta Verapaz, Guatemala. Ecology of Food and Nutrition 31, 127-145.

Brune M, Rossander L \& Hallberg L (1989) Iron absorption and phenolic compounds: importance of different phenolic structures. European Journal of Clinical Nutrition 43, 547-558.

Bulux J, Quan de Serano J, Guiliano A, Parez R, Lopez CY, Rivera C, Solomons NW \& Canfield LM (1994) Plasma response of children to short term chronic beta carotene supplementation. American Journal of Clinical Nutrition 59, 369-375.

Caballero JN \& Mapes CS (1985) Gathering and subsistence patterns among the P'urhepecha Indians of Mexico. Joumal of Ethnobiology 5, 31-47.

Charlton RW (1983) The effects of organic acids, phytates and polyphenols on the absorption of iron from vegetables. British Journal of Nutrition 49, 331-342.

Combs GF, Welch RM, Duxbury JM, Uphoff NT \& Nesheim MC (editors) (1995) Food-based Approaches to Preventing Micronutrient Malnutrition: An International Research Agenda. Summary Report of an International Workshop. Ithaca, NY:
Cornell International Institute for Food, Agriculture and Development, Cornell University.

Cook JD \& Monsen ER (1976) Food iron absorption in human subjects. 3. Comparison of the effect of animal proteins on non-heme iron absorption. American Journal of Clinical Nutrition 29, 859-867.

De Maeyer EM with the collaboration of Dallman P, Gurney JM, Hallberg L, Sood SK \& Srikantia SK (1989) Preventing and Controlling Iron Deficiency Anemia Through Primary Health Care. A Guide for Health Administrators and Programme Managers. Geneva: WHO.

Dikshit SN, Udipi SA, Rao A \& Manoharan V (1988) Separation of carotenoids and estimation of beta carotene content of selected Indian food preparations by HPLC. Journal of Food Science and Technology 25, 39-41.

Florentino S (editor) (1996) Dietary Guidelines in Asian Countries: Towards a Food-based Approach. Proceedings of a Seminar and Workshop on National Dietary Guidelines, Meeting Nutritional Needs of Asian Countries in the 21st Century. Singapore: ILSI, Southeast Asia.

Food and Agriculture Organization (1996) World Food Summit. Rome Declaration on World Food Security and World Food Summit Plan of Action. Rome: FAO.

Food and Agriculture Organization (2000) The State of Food Insecurity in the World. Rome: FAO.

Food and Agriculture Organization and International Life Sciences Institute (1997) Preventing Micronutrient Malnutrition: A Guide to Food Based Approaches - A Manual for Policy Makers and Programme Planners. Washington, DC: ILSI Press.

Food and Agriculture Organization/World Health Organization (1988) Requirements of Vitamin A, Iron, Folate and Vitamin B12. Report of a Joint FAO/WHO Expert Consultation. Food and Nutrition Series no. 23. Geneva: WHO.

Food and Agriculture Organization/World Health Organization (1992) International Conference on Nutrition. World Declaration and Plan of Action for Nutrition. Rome: FAO. 
Gibson RS \& Ferguson E (2000) An Interactive 24 Hour Recall for Assessing Dietary Adequacy of Iron and Zinc Intakes in Developing Countries. Washington, DC: ILSI Press.

Gibson RS, Hotz C, Temple L, Yeudall F, Mtitmuni B \& Ferguson E (2000) Dietary strategies to combat deficiencies of iron, zinc and vitamin $\mathrm{A}$ in developing countries: Development, implementation, monitoring and evaluation. Food and Nutrition Bulletin 20, 219-230.

Hallberg L \& Rossander L (1984) Improvement of iron nutriture in developing countries: comparisons of adding meat, soy protein, ascorbic acid, citric acid and ferrous sulphate on iron absorption from a simple Latin American-type of meal. American Journal of Clinical Nutrition 39, 577-583.

Hanumatha Rao D, Mathur YN, Radhaiah G \& Prahalad Rao N (1986) Health and Nutritional Status of Tribals in Madhya Pradesh. Hyderabad, India: National Institute of Nutrition.

Hussain L \& El-Tohamy M (1988) Effect of supplementation with vitamin A or plant carotenes on plasma retinol levels among young Egyptian males. International Journal of Vitamin and Nutrition Research 59, 229-233.

Hussain L \& El-Tohamy M (1990) Vitamin A potency of carrot and spinach carotenes in human metabolic studies. International Journal of Vitamin and Nutrition Research 60, 229-235.

International Institute of Population Studies (1998) National Family Health Survey of India 1994-1996. Bombay, India: IIPS.

Kataria A, Chauhan BM \& Gandhi S (1988) Effect of domestic processing and cooking on the antinutrients of black gram. Food Chemistry 30, 149-156.

Kearney M \& Gibney MJ (1994) Qualitative research by focus group discussion to identify concerns about weight among adult females. Proceedings of the Nutrition Society 53, $120 \mathrm{~A}$.

Krause VM, Kuhnlein HV, Lopez-Palacios CY, Tucker KL, Ruz M \& Solomons NW (1993) Preparation effects on tortillas mineral content in Guatemala. Archivos LatinoAmericanos de Nutricion 43, 73-77.

Lynch SR, Hurrell RF, Dassenko SA \& Cook JD (1989) The effect of dietary proteins on iron bioavailability in man. Advances in Experimental Medicine and Biology 248, 117-132.

Marfo EK, Simpson BK, Idowu JS \& Oke OL (1990) Effect of local food processing on phytate levels in cassava, cocoyam, yam, maize, sorghum, rice, cowpea and soybean. Journal of Agricultural and Food Chemistry 38, 1580-1585.
National Nutrition Monitoring Bureau (2000) Fifty Years of NNMB. Annual Report. Hyderabad, India: Indian Council of Medical Research.

Padmavati K, Udipi SA \& Rao M (1992) Effect of different cooking methods on carotene content of vegetables. Journal of Food Science and Technology 29, 137-140.

Prabhavathi T \& Rao N (1979) Effects of domestic preparation of cereals and legumes on ionizable iron. Journal of the Science of Food and Agriculture 30, 597-602.

Rahman MM, Mahalanabis D, Islam MA \& Biswas E (1993) Can infants and young children eat enough green leafy vegetables from a single traditional meal to meet their daily vitamin A requirements? European Journal of Clinical Nutrition 47, 68-72.

Rao Narasinga BS (1991) Use of beta carotene rich foods for combating vitamin A deficiency. NFI Bulletin 12, 1-6.

Reddy V \& Vijayaraghavan K (1995) Carotene Rich Foods for Combating Vitamin A Deficiency. Hyderabad, India: National Institute of Nutrition.

Sankara Rao DS \& Deosthale YG (1980) Effect of pearling on mineral and trace element composition and ionisable iron content of sorghum. Nutrition Reports International 22, 723-728.

Sankara Rao DS \& Deosthale YG (1981) Mineral composition, ionizable iron and soluble zinc in malted grains of pearl millet and ragi. Food Chemistry 11, 217-223.

Seshadri S, Shah A \& Bhade S (1985) Hematologic response of anemic preschool children to ascorbic acid supplementation. Human Nutrition: Applied Nutrition 39A, 151-154.

Thompson FE \& Byers T (1994) Dietary assessment resource manual. Journal of Nutrition 124, 2245S-2317S.

Tontisirin K \& Bhattacharjee L (1999) National policy on micronutrient deficiencies elimination. Regional Conference on Micronutrient Deficiencies Elimination, ILSI, Bangkok, September 1999. Bangkok, Thailand: ILSI, Southeast Asia.

Tontisirin K \& Gillespie S (1999) Linking community based programmes and service delivery for improving maternal and child nutrition. Asian Development Review 1, 1-33.

Tontisirin K \& Yamborisut U (1995) Appropriate weaning practices and foods to prevent protein-energy malnutrition: An Asian review. Food and Nutrition Bulletin 16, 34-39.

Yip R (1996) Prevention and control of iron deficiency in developing countries. Current Issues in Public Health 2, 253-263. 